\title{
Re-definition of Occupational Safety and Health Performance in Malaysian Manufacturing Industry
}

\author{
Mohd Nasir Selamat, Mukhiffun Mukapit, Siti Fardaniah Abd Aziz, Zafir Khan Mohamed \\ Makhbul
}

\begin{abstract}
Occupational safety and health (OSH) aspect in organization plays an important role in enhancing workers and job performance. This study aim is to conduct a systematic review of the literature on the definition of $\mathrm{OSH}$ performance in order to generalize the concept of $\mathrm{OSH}$ in organization. The search strategy targeted several electronic databases and identified more than 1000 potential articles. By focusing on the issues of $\mathrm{OSH}$ aspect in organization, few articles were examined (assessed with at least one related $\mathrm{OSH}$ aspects, published in Malay and English in peer reviewed literature). At the end, several articles met relevance criteria and were then appraised for methodological strength. The result shows varieties of definition and concept of $\mathrm{OSH}$. The main purpose of implementing $\mathrm{OSH}$ at work is to reduce all safety and health problems affecting workers and those that related to workers' connection with the organization. Therefore, a good implementation of $\mathrm{OSH}$ at work is required in order to achieve the organization's objectives. In conclusion, $\mathrm{OSH}$ aspects have respective diversity approaches to enhance workers' well-being and performance at work.
\end{abstract}

Keywords: Occupational Safety and Health (OSH), Workers performance, Job Performance

\section{INTRODUCTION}

In general, performance can be conceptualized and measured at broader levels, either in groups, organizations, or industries. This study seeks to investigate $\mathrm{OSH}$ performance as it relates to ability, as well as behavioral aspects in the context of OSH that contribute to various workers' outcomes. It also seeks to promote and maintain the physical, mental, and social well-being of workers at the workplace, all of which are major concerns in the context of OSH. Encouraging and implementing aspects of OSH will assist in enhancing both worker and organizational performance.

Overlooking the importance of maintaining workers' health and social well-being at work will lead to numerous problems to both the

Revised Manuscript Received on September 25, 2019

Mohd Nasir Selamat, Centre of Human and Societal Wellbeing, Faculty of Social Sciences and Humanities, Universiti Kebangsaan, Malaysia, Bangi, Malaysia. Email: md_nasir@ukm.edu.my

Mukhiffun Mukapit, Technical University of Malaysia, Malacca, Malaysia.

Siti Fardaniah Abd Aziz, Centre of Human and Societal Wellbeing, Faculty of Social Sciences and Humanities, Universiti Kebangsaan, Malaysia, Bangi, Malaysia.

Zafir Khan Mohamed Makhbul, School of Management, Faculty of Economics and Management, Universiti Kebangsaan, Malaysia, Bangi, Malaysia. individuals as well as the organization. Specifically, this may lead to a loss of workers' talents and decrease in organizational performance. Therefore, it is necessary to promote and maintain highest degree of physical, mental, and social well-being of individuals in all occupations to ensure their performance at work.

At an individual level, low levels of health outcomes, may affect not only individual's own quality life but also their relationship with others. For instance, general mental depression will lower individual's normal capability to perform but may also drive away friends and family because the negative response he/she may demonstrate due to the depression; this contributes to the increase in amongst six Asian countries in which, in Malaysia, it is found that $48 \%$ out of 532 Malaysian respondent suffered from some minor health, while $30 \%$ of Malaysian women and seven per cent of men had major health issues (News Strait Time on September 20, 2015). These eventually may result to other social illness in the long run.

On the other hand, companies with the highest health problems, poor facilities, and environmental problems as well as poor working environment will lead to decrease level of employees' work performance [1]; [2]; [3]. Consequently, it could affect organizational performance, such as increase in organizations cost due to work delay, accident, and inefficiencies.

In addition, at the organization level, occupational safety and health can incur higher operational cost. For instance, work-related accidents and injuries significantly affect the cost of insurance premiums paid by companies [4]; [5]; [6]. The cost of workers' medical benefits increases with a high incident of accidents and injuries, which eventually, adds to the administrative costs, in which organization have to pay higher insurance premium [7]; [8]. Unhealthy and unsafe workplace would also increase medical bills. Moreover, if the OSH problem continues, it is predicted to involve in higher compensation pay out and resulted in higher administration cost to the organization and government.

Based on previous available literature, it is demonstrated that little effort was spent on clarifying the $\mathrm{OSH}$ performance concept in the workplace [9]; [10]. 
Thus, the further discussion on the issues is needed. Hence, the objective of this study is to answer the question of does OSH performance has a standard definition around the world and how does it affect the implementation of $\mathrm{OSH}$ aspects in the organizations. This is important to show that OSH issues actually carry significant insight into humanitarian considerations, financial cost, legal sanctions and at the end workers and organizations performances.

\section{METHODOLOGY}

References are made on related studies since 1980, which present models and theories that indicate the significant of $\mathrm{OSH}$ at the workplace. Henceforth, these include several research studies from abroad and local through manual online search. The search strategy targeted several electronic databases and identified more than 1000 potential articles. By focusing on the issues of OSH aspects in organization, a few articles were examined (assessed with at least one related $\mathrm{OSH}$ aspects, OSH performance, OSH in organization, manufacturing industries and related issues, published in Malay and English in peer reviewed literature). Electronics databases including OSH Abstract Online, Scopus, ProQuest Digital Dissertations, Foreign Doctoral Dissertation and Thesis and other databases were reviewed to achieve current study's objective. Proceeding from different conferences, books and book chapters, annual report and relevant documents were manually reviewed. There are a few criteria that applied in order to get a good and quality references and it followed by the parameters: 1) Period of papers/books publication - not limitation due to design the understanding of concept; 2) Key descriptors: occupational safety and health $(\mathrm{OSH})$, fundamental of $\mathrm{OSH}$, OSH in organization, OSH performance; 3) Databases: Ebsco Host, Science Direct and Scopus.

We first review the conceptual basis of OSH's definition through experts and others studies. Then, several definitions were integrated into the operational definition, which is suitable to achieve the present study. Moreover, major concern in OSH including elements of occupational accident, absenteeism, occupational stress and sickness are integrated as the OSH's definition. Other than that, we report the comparison between OSH definitions with related workers performance in manufacturing industry.

Further, following discussion represent the OSH's definition referring to $\mathrm{OSH}$ performance in Malaysia. Finally, it is the utmost intention of the current study to reveal the importance of redefining the concepts of OSH performance at workplace in this new and challenging millennium era as well as to enhance safety and health issues at work. At the end, several articles met relevant criteria and were then appraised for methodological strength.

\section{RESULT AND DISCUSSION}

In the 18th and 19th centuries, OSH had become an important area of concern in many countries, especially in the United States. The focus of both many developed and developing countries on OHS at the workplace became increasingly complex. The complexities of today's safety and health hazards had mirrored the complexities associated with modern workplace technology at the workplace [11]. In this respect, it is important to develop a broad range of knowledge, as well as OSH- related skills, to ensure the well-being of a company's human capital and other resources. This includes workers and organization performance.

In Malaysia, Occupational Safety and Health Act (OSHA), was regulated by the Department of Occupational Health and Safety (DOSH), under the Ministry of Human Resources, which is responsible for updating and implementing $\mathrm{OSH}$ policies, as well as laws to ensure the health and safety of the work environment. OSHA seeks to promote an awareness of safety and health, as well as to instill a culture of safety and health among the entire Malaysian workforce. OSHA also seeks to ensure that all parties concerned, primarily employers and workers, are more responsible and accountable in their efforts to provide and maintain a safe and healthy workplace for the ever-growing labor force (OSHA, 2010).

The basic principles encompassed by OSHA are designed around the following six principles; (a) prevention of accidents is an important aspect of good management and skills, (b) management and those at the work site must cooperate in ensuring that workplaces are free from any accidents, (c) the involvement of top management is paramount in directing the implementation of workplace safety, (d) occupational safety and health policies should be drafted and acknowledged by all employees in the workplace, (e) organizations and resources need to be developed and provided in support of health and safety, and (f) the best available methods and knowledge need to be utilized. These six principles introduced through OSHA in 1994 thus sought to encourage workers' cooperation and participation, as well as involving employers directly in the field of $\mathrm{OSH}$, so as to overcome any potential problems arising at the workplace.

Nevertheless, according to Archer, Borthwick and Tepe [12] apart from the instinctive human concern for our own health and safety, and that of others, there are many other reasons for making OSH a priority. These include (a) community standards or expectations that organizations have a 
responsibility for those that work for them; (b) the loss of staff morale and potential industrial relations problems in the event of death, injury or disease; (c) legal obligations that require the workplace to be safe and healthy for employees as well as for contractors and visitors; (d) insurable costs, predominantly workers' compensation premiums, which are related to the claims experience of the organization and, to a large extent, controllable by the organization; (e) non-insurable costs associated with workplace injury, such as lost time, reduced productivity, staff replacement and retraining costs, as well as loss of business reputation; (f) costs to the community, such as health services, rehabilitation, and loss of skilled labor; (g) costs to employees through reduced quality of life as a result of workplace injury and disease, reduced income for the injured and their family, and the grief endured by everyone involved.

On the other hand, OSH in Malaysia has come a long way from the traditional approach, integrating industrial hygiene into the concept of self-regulation, and integrating human and organizational factors into the management of occupational safety and health [13]. As such, $\mathrm{OSH}$ at the workplace undoubtedly needs to be implemented as soon as possible because it would provide a chance to improve the performance of both employees and the organization itself.

Performance refers to the achievement of employee's behavior while doing their work in good condition. It also depends on the employee's ability to be able to perform under simulated conditions [14]. It refers to behavioral aspects that contribute outcomes to the organizations [15], which is not defined by the action itself, but by judgmental and evaluative process [16]. OSH refers to an act of making further provisions for securing the safety, health and welfare of persons at work, and for protecting others against risks to safety or health in connection with the activities of persons at work (OSHA, 2010). The purpose of OSH is to establish the National Council for Occupational Safety and Health and for matters connected therewith (OSHA, 2010). In other words, it means promoting and maintaining the highest degree of physical, mental, and social well-being of workers in all occupations [12]. In general, $\mathrm{OSH}$ performance can be defined as the look on the restraint in preserving and protecting individual workers and facility resources at the workplace including social, mental, physical, and well-being aspects. It also focuses on preventing the occurrence of several safety and health-related problems including: absenteeism, sickness, occupational stress, and occupational accidents [2]; [3].

Previous theory has shown three indicators, namely absenteeism, sickness, and occupational stress as major concerns of workers' outcome.
Moreover, occupational accidents were found to be the most important measure of OSH performance [17]; [12]; [9]; [2]. Therefore, occupational accidents should be included as another indicator of $\mathrm{OSH}$ performance as this has yet to be done. In addition, this study will extend the traditional theory by integrating a new element into measuring safety in the balance theory [18]. In turn, this will enable organizations and workers to carry out their work accurately, while improving safety at the workplace by preventing injuries and near accidents.

\section{DEFINITION OF OSH PERFORMANCE}

It is widely acknowledged that job performance is represented by a person's observable actions or behaviors, reflecting their knowledge or skills acquired from formal or informal training and used for meeting work task demands. The performance of a worker is best appraised by measuring a person's actions, behaviors, knowledge and skills against certain criteria or standards [14]. It is also recognized that worker's performance is important as it influences overall organizational performance. By measuring the performance of individual workers, it is possible to indicate the extent of learnt behavior as a result of training received at work and its effect on organizational performance.

One of the work behaviors expected from a worker is to perform safe work practices. For instance, a building laborer is expected to wear personal protection equipment (PPE) and practice safety at the work site, whereas a nurse is expected to wear gloves or a mouth cover to prevent contracting a communicable disease when handling high-risk patients. These safe work practices are usually learnt during formal worker training to ensure an appropriate level of worker performance, and are increasingly considered part of a worker's overall job performance.

Workers that failed to execute safe work practices would be considered failed to display OSH performance. Failure to adhere to safety work environment will be expected to lead to several hazardous consequences to safety and health that could be measured. For example, stressful experience, sickness, absence from work and unmotivated to attend because attending at work may be dangerous to the workers. These consequences are usually more destructive to work performance than considered as just challenging task for workers.

Safe work practices are an integral element of OSH implementation. Enhanced worker safety and health on the job are key outcomes of OSH, which guides workers to prevent any safety and health related problems that can affect their ability to do their job or affect their performance, and the 
overall performance of the organization. Thus, aspects on the OSH issues could be given consideration in order to achieve a higher performance.

Aspects of safety and health of workers such as maintaining the highest degree of physical, mental, and social well-being of workers, is a crucial issue in an organization's environment. Not surprisingly, several studies have reported improvements in both organizations' and workers' performance is due to implementation of $\mathrm{OSH}$ aspects [19]; [20]. For example, study by Seok [21] claimed that a good safety and health management system at work comprise of hinder occurrences of accidents, and enhance worker's awareness of safe working practices. Thus, since workers' safety and health plays an important role in achieving better performance, a broad understanding of the terms 'safety' and 'health' encourage workers and organizations to implement $\mathrm{OSH}$, irrespective of occupation.

Ludin [22] has claimed that 'safety' involves a positive sense of security in an environment, one that is free from hazards of all types. Safety also encompasses the protection of employees, properties, and profit of an organization while work is being done. A discussion of safety may include worker perception of feeling safe, methods of achieving safety, and the likelihood of incurring losses. In addition to safety, the term 'health' is generally synonymous with the absence of disease, which is carefully defined and classified. The World Health Organization (WHO) (1998) and Archer, Borthwick, and Tepe, [12] have reported that 'health' is a state of complete physical, mental, and social well-being, and not merely the absence of disease or infirmity. Moreover, the Organization for Economic Cooperation and Development (OECD) defines 'health' as a physical, psychological, mental, and social state of tolerance and compensation, outside the limits of which the individual perceives any situation.

Furthermore, there is a well-accepted agreement on the importance of OSH performance to avoid unforeseen disasters, at both the individual and organizational level, there seems to be a lack of consensus on an agreed definition of $\mathrm{OSH}$ performance. For this reason, to propose terms of OSH performance, a review of OSH definitions has been made before commencing a discussion on evaluation methods of OSH performance.

These definitions of health can be summarized to a perceived state of individual opinions on his/her physical, mental, and social well-being. Thus, both terms, safety and health, can be occasionally used interchangeably to refer to $\mathrm{OSH}$ issues, depending on usage or the context. For example, previous study was used to define the concept of OSH intervention in assessing safety and health matters such as applying personal protection equipment to workers, which include the context of developing, implementing and evaluating safety and health [23]. Therefore, in this study, OSH refers to safety and health issues in the workplace, and the terms 'safety' and 'health' also refer to OSH issues and aspects, and should be understood within the relevant context.

According to Occupational Health and Safety Advisory Services, (OHSAS 18002:2000) [24], OSH means the conditions or factors that affect the well-being of not only employees, but also affect to the people around the workers or do come into contact with the workplace such as temporary workers, contractor personnel, visitors and customers. The preservation of facilities and resources in an organization is also an OSH concern. The variations on this definition have been outlined by Kohn et al. [11] who defined $\mathrm{OSH}$ as a discipline concerned with preserving and protecting human and facility resources in the workplace. Thus, OSH requires the maintenance of not only people whom are workers and those having some relationship with the workplace but also maintaining zero hazard of machines and work tools [2].

This is similar to the OSH aims from the ILO and WHO, namely to prevent industrial accidents, hazards, and disease, and at the same time recognize the connection between workers' health and safety. This demonstrates the reason why such data are generated to monitor the level of OSH status/performance. Thus, if OSH is monitored and employed well, it should address worker's sickness, absenteeism problem and improves job performance.

Based on an earlier discussion, there is a recognized connection between worker health and safety and worker performance. This suggests that OSH, which enhances worker safety and health, needs to be well implemented, and its performance measured, at work. It can be referred to the definition of performance in the context of OSH that claimed by Cohen and Colligan [25]; in which, to mean complying with safe work practices, using protective equipment as prescribed, demonstrating increased awareness of hazards by reporting unsafe conditions in order to prompt corrective efforts, and executing emergency procedures should such events occur. Some organizations measure their workers' safety performance, which indicates the level of OSH achievement in the organization, and its relationship to $\mathrm{OSH}$ compliance. Therefore, by measuring OSH achievement, organizations are also able to measure overall organizational OSH performance. Thus, in ensuring OSH performance, workers are promised a safe and healthy work environment, which will ensure job performance.

It is important to measure OSH performance, to do so with the purpose of preventing or controlling losses is the overriding priority. Thus, in order to support the conceptualization of $\mathrm{OSH}$ performance, the current 
study tried to re-define the concept of OSH performance with the combination OSH related aspects. If OSH performance is determined when safety work practices are observed, a few of its immediate consequences can be seen by reducing accidents, zero absenteeism, and sickness. Therefore, this could be ideal technique of measuring OSH performance.

According to Health, Safety, and Environment Policies of Government in the United Kingdom, measuring OSH performance cannot be achieved through a single measure of safety and health performance (HSE, 2012). Yet, it seems to be a consensus among safety professionals that measuring $\mathrm{OSH}$ performance helps an organization to attain some note-worthy improvements in its safety performance [26]. Safety practitioners and professionals recognize many different methods of measuring $\mathrm{OSH}$ performance, depending on the objective and appropriateness to the nature of an organization's operations. Therefore, an important element of $\mathrm{OSH}$ is to ensure that individual workers and the organization as a whole understand the concept and importance of measuring $\mathrm{OSH}$ performance. One possible measurement refers to the approach of preventing hazards and accidents at work to raise worker's safety levels. In contrast, if hazards and accidents at work not a high priority, the means of addressing safety issues is given less attention in the workplace.

Previous studies reveal that the concept of OSH performance encounters conceptual confusion [27], and this confusion lies in the purpose of measuring $\mathrm{OSH}$ performance. Depending on the aims of OSH at work, different studies have used different words or terms to explain OSH performance. Safety performance, safety compliance, safety programs, safety culture, and others have been used to explain OSH issues and performance [28]; [29]; [5]. Interestingly, all these terms commonly share an equivalent meaning, which is to enhance worker safety and health, and to safeguard workers to the highest degree of physical, mental, and social well-being [2].

One important element of measuring safety performance, mentioned by Toellner [30], is the need for management and workers to understand whether their safety efforts actually do prevent accidents and illnesses. Grimaldi and Simonds [27] argue that measuring OSH performance with the purpose of preventing measurable accidents is not only inadequate, but also too idealistic to be pursued satisfactorily. This means that if the purpose of measuring $\mathrm{OSH}$ performance is to count incidents, such as near misses or near hits - which have the potential to cause harm, injury, property damage, or losses - it fails. This is because measuring OSH performance could be an objective and subjective. If measuring through incident rate, it is only focus on objective, which refers to figures such as data of statistic, day of loss and others. Yet, these are not measuring subjective aspect, such as the understanding of further circumstances affecting the objective measurement. Importantly, subjective measurement of OSH contributes to more in depth and clear result or justification about the $\mathrm{OSH}$ performance and implementation.

Apart from this issue, industrial psychology practitioners consider that physical effects (accidents), hazards, and injuries can have psychological consequences that are detrimental to the emotional well-being of workers [14]. For example, those who are involved in extreme accident at work such as cutting hand, have probability to face with trauma that affected workers psychological and emotion. Obviously, safety incidents at work are likely to affect individuals both physically and emotionally, as well as affect their work performance. These potential issues with $\mathrm{OSH}$ measurement refocus the essence of $\mathrm{OSH}$ on three important elements, refers to physical aspects, mental stability, and social well-being that lead to enhanced worker performance.

Other study claim that OSH performance measurement could results the over- design of the workplace/workstation, a large OSH staff in the organization and ever- expanding OSH budgets (Webb, 1994). Similarly, Cohen [31] reported that big companies, such as Motorola and General Electric, use the Six Sigma Safety approach in measuring safety and health performance at work. This method employs a process of Define, Measure, Analyze, Improve, and Control (DMAIC) to improve effectiveness and efficiency, with the aim of reaching zero safety and health problems. A study by Lateef [29] examined safety management performance in the manufacturing industry in Saudi Arabia utilizing the six-sigma approach in measuring safety management performance. Thus, in order to measure safety performance at work, commitment and effort is the main important factor. This means that, it goes to several resources including human resources, good financial support, excellent administration and others [2].

Another approach to measuring safety performance is described by Burke et al. [32] who concluded that general measurements of safety performance could be based on four constructs. These constructs are (i) using personal protective equipment, (ii) engaging in work practices that reduce risk, (iii) communicating health and safety information, and (iv) exercising employees' rights and responsibilities. An important element of this construct-based method is that organizations need to address any hindrances to effective measurement, particularly when evaluating safety and health outcomes. In other words, management also plays critical role in preventing any safety and health related problems at work.

The work of Muhammad [33] expands 
upon this, suggesting that in order to achieve OSH objectives, a number of players are also determined as important in achieving $\mathrm{OSH}$ performance. These include personal's management, workers, clients, and officials union of the company. Specifically, individuals interact with others in the workplace, such as superiors, subordinates, and peers, generating two-way communication that assists them in achieving good work performance. This is because $\mathrm{OSH}$ performance can be seen into the many aspects of organization as explain above. Therefore, information related to the $\mathrm{OSH}$ aspect could be generated from each party that engages with those divisions.

Yet, sometime workers may face conflicts while presenting safety or health issues in the workplace. This need to be solved before any other problems emerges. Webb [34] suggested several actions to be taken to improve communication, reduce the potential for workplace conflict, and ensure OSH objectives. These can be successfully achieved through; (a) putting management processes in place that ensure safety issues are reflected in any changes in equipment, operations, organization and regulations; (b) train new staff and refresh existing staff; (c) conduct regular audits and reviews; (d) communicate environmental, health and safety awareness through coordinated publicity campaigns, meetings, newsletters and other mechanisms. These represent the OSH performance of workers, through which interaction enhances workers' performance.

Measuring OSH performance is assumed as a baseline of maintaining workers' good health. In conducting this study, researcher presumes that workers must be in a good physical condition, mentally stable, in good state of social well-being and safe from the risk of injury or accidents. Worker characteristics and individual background as well as the work environment itself, all have impact on OSH performance. For example, workers' backgrounds (age, gender, skill, experience, level of health) need to be considered, as well as the workplace environment. Several studies have reported that poor work environment contributes to the occurrence of accidents at work and increases workers' stress [35]; [36]; [37]. In addition, individual behaviors related to OSH are an important consideration, and Smith and Carayon [38] outlined a number of poor work environment in their Balance Theory. For example, absenteeism and sickness issues among workers can be a major concern in the measurement of $\mathrm{OSH}$ performance when the reasons behind these behaviors are related to safety or health issues.

Thus, it can be said that measuring $\mathrm{OSH}$ performance, which strives to protect individual workers and facility resources at the workplace, should include a range aspect of workers' behavior that linked to their social, mental, physical, and general well-being; in which lead to better employee performance [11]. Workers are considered to be performing in an occupationally safe and healthy environment when they display excellent physical aspects (a good level of health, unaffected by injuries and accidents), good mental stability (low stress and mental strain levels), and a good state of social well-being (feeling happy at work and enjoying a good relationship with employers and other employees). In other words, measuring $\mathrm{OSH}$ performance is also related to an individual worker's health.

Aspects of physical safety and security need to be given attention, including psychological and social needs, such as having agreeable peers and co-workers, enjoying respect, exercising a certain level of control over their lives, being able to communicate openly, and exploring other interests freely with others [12]. These aspects lead to a better quality of life and create a sense of well-being that helps the achievement of good levels of $\mathrm{OSH}$.

With regard to workers' psychological and social needs, occupational stress can also be measured as one OSH performance's indicator [39]. An earlier study also found that workers' poor performance could be due to stress or other emotional problems, stemming perhaps from extreme pressure or a medical disorder [40]. These psychological, behavioral, or physiological problems can reduce workers' attention to work in focus and consequently could alleviate to higher absenteeism and sickness [41]; [42]; [43]; [44]. This situation is also part of maintaining health at work and can become an OSH performance concerns.

The previously outlined obstacles to OSH performance are varied, Gallagher [45] identifies three additional factors, or barriers to improved performance: (a) the lack of knowledge by senior managers of health and safely principles, legislation and management systems; (b) a limited and reactive role for health and safety supervisors, typically associated with limited time, resources and support in attending to health and safety; and (c) an over-reliance on health and safety specialists to drive health and safety activities without sufficient management involvement and support. Another study also highlights the obstacles in determining organizational safety performance, which are, (i) the culture or system, (ii) behavior, (iii) safety programs, and (v) learning or growth. These four determinants, according to Ingalls [46], are measurable and drive safety and health performance.

Thus, to overcome obstacles to OSH performance, a good measurement system needs to be in place that identifies potential issues and facilitates proactive remedial actions. Effective measurement of $\mathrm{OSH}$ performance in organizations should observe multiple aspects, such as physiological, psychological, psychosocial aspects, as well as the physical 
environment [2]. Such measures, coupled with proactive remediation, could support organizational development and the achievement of organizational missions and goals.

\section{CONCLUSION}

The knowledge and acceptance of OSH performance concepts at work plays an important role in enhancing the productivity of workers and the organization as a whole. OSH performance plays major role in enhancing the concept of safety and health at work. As mentioned by Carayon's [18] which the safety and health issues contribute to the extension to the potential outcome for workers and organizations. Thus, issues on the absenteeism, worker's sickness, occurrences occupational stress and occupational accident, would representing new OSH performance; which shows that if these issues are not given attention, it will affect to the performances of workers and organizations.

Furthermore, the main purpose of implementing OSH at work is to hinder all the safety and health problems to the workers and related persons connect with the organizations. Nevertheless, the examination of literature has implicitly indicated that $\mathrm{OSH}$ performance can be used to improve the quality of workers in the workplace [2]. Therefore, good implementation of OSH at work is required in order to achieve organizational objectives. Finally, it is shown that OSH aspect has a diversities respectable approach in enhancing workers well-being and performance at work.

\section{REFERENCES}

1. Selamat, M. N. \& Surinty, L. (2015). An Examination of Commuting Accident in Malaysia. Journal of Occupational Safety and Health, 12 (1), 171-178. ISSN 1675-5456.

2. Selamat, M. N. (2016). Ergonomic Work System and Occupational Safety and Health Performance: Mediating Effects of Psychosocial Work Factors. Doctoral Philosophy Thesis, Universiti Sains Malaysia, Penang, Malaysia.

3. Selamat, M. N. \& Mukapit, M. (2018). The Relationship Between Task Factors \& Occupational Safety and Health (OSH) performance in the printing industry. Akademika. ISI ESCI Indexed

4. Shan, C. W. (2011). Quantitative approach to site accident in Malaysia. Unpublished bachelor degree dissertation, Faculty of Engineering and Science, Universiti Tunku Abdul Rahman, Kuala Lumpur, Malaysia.

5. Yakubu, D. M., \& Bakri, I. M. (2013). Evaluation of safety \& health performance on construction sites (KL). Journal of Management and Sustainability, 3(2).

6. Zakaria, N. H., Mansor, N., \& Abdullah, Z. (2012). Workplace accident in Malaysia: Most common causes and solutions. Business and Management Review, 2(5), 75-88.

7. Ayers, P. A., \& Kleiner, B. H. (2002). New development concerning managing human factors for safety. Managerial Law Journal, 44.

8. Smith, M. J., \& Carayon, P. S. (2000). Work organization and ergonomics. Applied Ergonomics, 31, 649-662.Tetrick LE, eds. Handbook of occupational health psychology. Washington, DC: American Psychological Association, 2003:123-42.

9. Selamat, M. N. (2013). The determinant of OSH performance: A study on ergonomic work system. 23rd Conference on Epidemiology in Occupational Health (EPICOH 2.0.13): Improving the Impact. June 18-21, 2013, Utrecht, The Netherlands. Published at the Journal Occupational Environmental Medicine, 2013, 70: A4. doi: 10.1136/oemed-2013-101717.139.
10. Hasse, N., Birgitta, W., Hans, H., Ragnar, W. (2017). A cross-sectional study of factors influencing occupational health and safety management practices in companies. Safety Science 95, 92-103

11. Khon, J. P., Friend, M. A., \& Winterberger, C. A. (1996). Fundamental of occupational safety and health. Industrial Technology Department, East Carolina University, Greenville, North Carolina.

12. Archer, R., Borthwick, K., \& Tepe-Susanne. (2009). OS\&H a management guide. Engage Learning Australia 2009.

13. Hazlina, Y. (2007). Factors associated with chemical safety status in small and medium Printing Enterprises in Penang. Masters Thesis, Universiti Sains Malaysia, Penang, Malaysia.

14. Spector, P. E. (2008). Industrial and organizational psychology. 5th Edition. John Wiley \& Sons, LTD.

15. Campbell, J. P., McCloy, R. R., Oppler, S. H., \& Sager, C. E. (1993). A theory of performance. In E.Schmitt, W. C. Borman, \& Associates, (Eds). Personnel selection in organizations. San Fracisco: Jissey-Bass. 35-70.

16. Motowildo, S. J., Borman, W. C., \& Schmit, M. J. (1997). A theory of individual differences in task and contextual performance. Human Performance, 10, 71-83.

17. Ahmadon, B., Rosli, M. Z., Mohd-Saidin, M., \& Abdul-Hakim, M (2006). Occupational safety and health (OSH) management systems: towards development of safety and health culture. Proceedings of the Sixth Asia-Pacific Structural Engineering and Construction Conference (APSEC 2006), 5-6 September 2006, Kuala Lumpur, Malaysia.

18. Carayon, P. (2009). The Balance Theory and the Work System Model... Twenty years later. INTL. Journal of Human-Computer Interaction, 25(5), 313-327.

19. Khoo, T. H. (2012). Safety management practices and safety behavior: A study of SME in NCER, Malaysia. Unpublished Master of Art (Management), Universiti Sains Malaysia, Penang, Malaysia.

20. Salleh, A. L., Abu-Bakar, R., \& Keong, W. K. (2008). How detrimental is job stress? A case study of executives in the Malaysian furniture industry. International Review of Business Research Papers, 4(5), 64-73.

21. Seok, J. Y., Hsing, K. L., Gang, C., Shinjea, Yi., Jeawook, C., \& Zhenhua, R. (2013). Effect of occupational health and safety management system on work-related accident rate and differences of occupational health and safety management system awareness between Managers in South Korea's Construction Industry. Safety and Health at Work, 4, 201-209.

22. Ludin, E. (1994). Health and Safety Management. Ministry of Human Resource Bulletin, Special Edition. National OSH campaign towards safe and healthy work culture. 45-59.

23. Donato, M., Enrico, C., \& Guido, J. L. M. (2014). Developing, implementing and evaluating OSH interventions in SMEs: A pilot exploratory study. International Journal of Occupational Safety and Ergonomics (JOSE), 20(3), 385-405.

24. Seabrook, K. A., \& Winterholer, B. (2006). The American society of safety engineer. http://www.asse.org/practicespecialties/interviews/SeabrookWinterhole r.php

25. Cohen, A., \& Colligan, M. J. (1998). Assessing OSH Training: A Literature Review, DHHS (NIOSH) Publication, 98-145.

26. Cohen, J. M. (2002). Measuring safety performance in construction. Occupational Hazard, 64(6), 41-45.

27. Grimaldi, J. V., \& Simonds, R. H. (2001). Safety management, 5th Edition. Delhi: A.I.T.B.S. Publishers \& Distribution.

28. Gerard, I. J. M. Z, Arjella, R., van-Scheppingen, Evelien, H. B., Anja, D., \& Annick, S. (2013). The core values that support health, safety, and well-being at work. Safety and Health at Work, 4(4), 187-196.

29. Lateef, Ur-Rehman \& Ateekh, Ur-Rehman. (2012). Safety management in a manufacturing company: Six Sigma Approach. Engineering, 4, 400-407.

30. Toellner, J. (2001). Improving safety \& health performance: Identifying and measuring leading indicators. Professional Safety, 42-47.

31. Rancour, T., \& McCracken, M. (2000). Applying six sigma methods for break through safety performance. Personal Safety, 29-32.

32. Burke, M. J., Sarpy, S. A., Tesluk, P. E., \& Smith-Crowe, K. (2002) General safety performance: A test of a grounded theoretical model. Personnel Psychology, 55, 429-457. 
33. Muhamad, s. (2003). Scorecard Approach to Benchmarking Organizational Safety Culture in Construction, Journal of Construction Engineering and Management, 123 (1).

34. Webb, D. A. (1994). The bathtub effect: Why safety programs fail. Management Review, 83(2), 51.

35. Nikolaos, G. (2010). The Measurement of health and safety conditions at work theoretical approaches, tools, and techniques a literature review. International Research Journal of Finance and Economics, 36.

36. Saad, M. S., Said, F., \& Abdul-Halim, Z. (2012). The determinants of industrial accidents in the Malaysian manufacturing sector. African Journal of Business Management, 6(5), 1999-2006.

37. Zafir, M. M., Nor-Liza, A., \& Zizah, C. S. (2013). Ergonomics and stress at workplace: engineering contributions to social sciences. Jurnal Pengurusan, 37, 125-131.

38. Smith, M. J., \& Carayon, P. S. (1989). A balance theory of job design for stress reduction. International Journal of Industrial Ergonomics, 4(1), 67-79.

39. Noblet, A., \& Lamontagne, A. D. (2006). The role of workplace health promotion in addressing job stress. Health Promotion International, 21(4), 346-353.

40. Zuraidah, O. (2001). Managing performance in Malaysian organizations; Series Editor: Maimunah Aminuddin. Mc Graw Hill, Kuala Lumpur.

41. Hesselius, P. (2007). Does sickness absence increase the risk of unemployment? The Journal of Socio-Economics, 36, 288-310.

42. Kerr, R., Mc Hugh, M., \& McCrory, M. (2009). HSE management standards and stress- related work outcomes. Occupational Medicine, 59, 574-579.

43. Michie, S., \& Williams, S. (2003). Reducing work related psychological ill health and sickness absence: A systematic literature review. Occupational and Environmental Medicine, 60, 3-9.

44. Shikdar, A. A., \& Sawaqed, N. M. (2003). Worker productivity and occupational health and safety issues in selected industries. Computer and Industrial Engineering, 45, 563-572.

45. Gallagher, C., Elsa U., \& Malcolm R. (2003) Occupational safety and health management systems in Australia: barriers to success, Policy and Practice in Health and Safety, 1:2, 67-81, DOI: 10.1080/14774003.2003.11667637

46. Ingalls, Jr. T. S. (1999). Using scoreboard to measures safety performance. Professional Safety, 44(2), 23-29.

\section{ACKNOWLEDGMENT}

Geran Galakan Penyelidik Muda (GGPM), UKM GGPM-2017-067

\section{AUTHORS PROFILE}

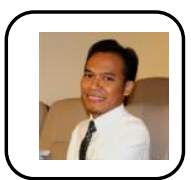

Mohd Nasir Selamat (Ph.D) is a Senior Lecturer at Centre of Human and Societal Wellbeing, Faculty of Social Sciences and Humanities (FSSK), Universiti Kebangsaan Malaysia (UKM). He is now holding leadership positions as Dean Assistant (Education \& Citra) at FSSK, UKM. His expertise and research interest are in the field of Human Resource Management and Development, Occupational Safety and Health, Ergonomics, and Occupational Training and Performance. He holds a Bachelor and Masters Degree of Science in Human Resource Development from University Technology of Malaysia, and Doctor of Philosophy in Human Resource Management from University of Science Malaysia. He also has experince in private industry as Human Resource Manager before joining UKM.

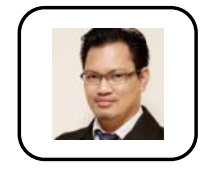

Mukhiffun Mukapit is a lecturer at Technical University of Malaysia, Malacca, Malaysia. He holds a Bachelor and Masters of Science in Human Resource Development from University Technology of Malaysia. He is a lecturer at the Faculty of Technology and Technology Management, Technical University of Malaysia. His expertise and research interest are in Management and Human Resource Development, Organizational Behavior And Entrepreneurship.

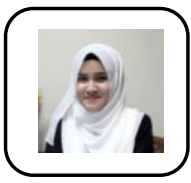

Siti Fardaniah Abdul Aziz (Ph.D) is a Senior Lecturer at Universiti Kebangsaan Malaysia /UKM (National University of Malaysia). She is now holding leadership positions as Head of Research Cluster and Intellectual Property Ambassador at Faculty of Social Sciences \& Humanities, UKM. She had her PhD. MSc., and BSc. in Human Resource Development field of study and have been involved as academics for more than 15 years. She was awarded for Outstanding Women in Management Award (2017) by Venus International Foundation, an international body of NGO. She had also received Excellent Service Award by UKM in 2015 and Outstanding Research Student Award by UPM in 2013. She has written more than 50 publications including books, magazine article, learning module, and journal articles indexed in ISI Q1, SCOPUS, ERA and other high indexed journals. She had also registered more than 10 copyrights of intellectual property including learning modules, instruments, and computer system related to Human Resource Development field of study. She had also lead more than 5 research grants within 5 years. She is also active in teaching, supervision, social services, academic writing, training, and research.

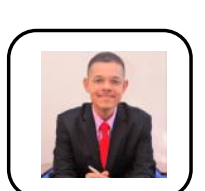

Zafir Khan Mohamed Makhbul (Ph.D) is a Professor at Faculty of Economics and Management, Universiti Kebangsaan (UKM), Malaysia, Bangi, Malaysia. He is now holding leadership positions as Deputy Dean for Undergraduate Affairs. Before joining UKM, he has industrial experience at Motorola, Hong Leong Bank and Agriculture Bank of Malaysia. His expertise and research interest are related to Human Resource Management and Organizational Behavior. He has written enormous books related to his expertise and some of hot selling books include Pengantar Pengurusan, Pengurusan Organisasi, Mengurus Perniagaan, Menjadi Usahawan, Pengenalan Kepada Pengurusan Sumber Manusia, and Asas Pemasaran. He is also active in teaching, supervision, social services, academic writing, and research. 